\title{
LOCAL DELIVERY OF TARGETED NANOPARTICLES AS THERAPEUTIC APPROACH TO OBLITERANS BRONCHIOLITIS AND MALIGNANT PLEURAL MESOTHELIOMA
}

\author{
FEDERICA MELONI (*), EMANUELA COVA (*), DAVIDE PILONI (*), \\ SIMONA INGHILLERI (*), GIULIA MARIA STELLA (*), \\ MIRIAM COLOMBO $(* *)$, DAVIDE PROSPERI $(* *)$
}

\begin{abstract}
SuNTO. - Il nostro lavoro ha come oggetto la ideazione e realizzazione di un nuovo approccio terapeutico a patologie respiratorie accomunate dal fatto di essere malattie rare, definibili orfane, con una prognosi molto limitata e scarse opzioni terapeutiche e suscettibili di un approccio terapeutico locale. La bronchiolite obliterante (BO) è caratterizzata dall'obliterazione fibrocicatriziale delle piccole vie aeree che si manifesta in seguito ad insulti immunologici ed infiammatori. Il mesotelioma pleurico maligno (MPM) è un raro tumore maligno che origina a livello pleurico, fortemente associato alla esposizione ambientale ad asbesto. Il nostro approccio consiste nell'ideazione di nanovettori (nanoparticelle d'oro, GNP) che possano essere caricati di specifici farmaci anti-proliferativi, aventi come bersaglio specifico le cellule responsabili dei due processi patologici (cellule mesenchimali fibroblastoidi nella BO, cellule di mesotelioma maligno in MPM) e adatti alla somministrazione per via locale (inalatoria o intrapleurica). Prima di tutto abbiamo isolato, messo in coltura e fenotipizzato delle cellule primarie da campioni di pazienti affetti da BO ed MPM. Una volta identificati alcuni bersagli presenti sulla membrana cellulare (CD44 per la BO e CD146 per MPM) abbiamo progettato un nanocostrutto carico dello specifico farmaco (everolimus/pemetrexed) e funzionalizzato con un anticorpo monoclonale sulla superficie esterna. Esperimenti in vitro su colture di cellule primarie patologiche hanno permesso di appurare come tali
\end{abstract}

(*) Università degli Studi di Pavia, Dipartimento di Medicina Interna, Sezione di Pneumologia, e Fondazione IRCCS Policlinico San Matteo, Pavia, Italia.

E-mail: f.meloni@smatteo.pv.it

${ }^{(* *)}$ Dipartimento di Biotecnologie e Bioscienze, Università degli Studi di Milano-Bicocca, Milano, Italia. 
nanoparticelle fossero in grado di penetrare specificamente nelle cellule bersaglio che esprimevano lo specifico recettore e non in altri tipi di cellule normali testate, eccezion fatta per il macrofago alveolare che presentava la tendenza a fagocitare anche particelle non funzionalizzate. La loro azione anti-proliferativa, pro-apoptotica ed anti-infiammatoria è stata provata in vitro. Si sono condotti anche esperimenti sull'animale per provare la mancanza di tossicità sia polmonare che extrapolmonare in seguito alla somministrazione per via inalatoria.

$* * *$

ABSTRACT. - Our work has the objective to develop and provide a new therapeutic approach to rare respiratory disease with poor prognosis. These diseases are united by the fact of being rare diseases, defined orphan, with a very poor prognosis and limited treatment options. Furthermore, they share the possibility to apply a local treatment with the advantage of decreased unwanted biodistribution and systemic toxicity. Bronchiolitis obliterans (BO) is a disease characterized by fibrotic obliteration of the small airways that occurs in response to inflammatory and immunological insults. Malignant pleural mesothelioma $(\mathrm{MPM})$ is a rare malignant tumor that originates from the pleura, strongly associated with environmental exposure to asbestos. Our approach consists in the creation of nanocarriers (gold nanoparticles, GNPs), which can be loaded with specific anti-proliferative drugs, specifically targeted to the cells responsible of the two pathological processes (fibroblastoid-like mesenchymal cells in BO, malignant mesothelioma cells in MPM) and suitable for administration by local street (inhaled or intrapleural). First, we isolated, cultured and phenotyped primary cells from patients from BO and MPM. Once you have identified some targets (CD44 for the BO and CD146 for MPM) we designed a nanotool loaded with the specific drugs (everolimus or pemetrexed) and decorated with monoclonal antibody on the surface. We performed experiments in vitro on primary cultures of pathological cells and we demonstrated that these nanoparticles were able to penetrate specifically in target cells expressing the specific receptor and not in other types of normal cells tested, except for the alveolar macrophages which presented the tendency to absorb the nanoparticles, also the not functionalized ones. The anti-proliferative, pro-apoptotic and anti-inflammatory action of these nanoparticles was tested in vitro. We have also conducted experiments in animals to prove the lack of both pulmonary and extrapulmonary toxicity following administration of nanoparticles by inhalation.

This work is based on the development of new fully biocompatible targeted drug-loaded nanovectors as a therapeutic approach of two rare pleura-pulmonary disorders characterized by a poor prognosis and a lack of effective therapeutic strategy. The two clinical entities (Bronchiolitis obliterans syndrome, BOS, and malignant pleural mesothelioma, MPM) have been chosen because they are orphan diseases with an urgent unmet therapeutic need, due to their poor prog- 
nosis and share the possibility to apply a local treatment with the advantage of decreased unwanted biodistribution and systemic toxicity.

Lung transplantation (LTx) represents a major burden for the health-care budget due to the costs of frequent hospitalizations, expensive medication and diagnostic procedures especially in patients with chronic lung allograft rejection (CLAD). BOS represents the major clinical phenotype $(70 \%)$ of CLAD and is responsible of the poorer long term survival observed among lung recipients compared to other solid organ transplants (Woodrow et al., 2010). BOS also occurs after allogenic bone marrow transplantation (as lung involvement in the context of chronic graft versus host disease). This disease is characterized by a fibrotic obliteration of small airways (Todd, 2011) due to a variety of immunological, infective or inflammatory insults, such as environmental exposure to irritants, infections, gastroesophageal reflux, chronic rejection or graft versus host disease. Patients with a BOS diagnosis suffer of a bad quality of life and unfavorable prognosis. The mean annual health-care costs for a stable LTx patient is about $€ 46,000$ and is $70 \%$ higher for patients with CLAD. To date no specific treatment is available to reverse or halt progression of airway obliteration and median survival is very poor (less than 3 years). The development of an effective treatment strategy might allow to improve long term outcome of LTx recipients and to reduce significantly hospital admission and mortality thus entailing a significant positive economic impact on disease management.

MPM is an aggressive tumor consequent to asbesto exposure affecting 1,200 patients in Italy and approximately 20,000 globally (Robinson et al., 2012). Due to the persistent asbestos exposure in many countries, a worldwide progressive rise in MPM incidence is expected during the coming decades. As a consequence of previous use of asbestos in several factories of northern Italy (as in Broni and Stradella in the province of Pavia), in certain area incidence of this tumour is 200 higher than mean national rate (data from Legambiente Italia, 2011) and its incidence is expected to increase until 2020. This such tumour therefore represents an unsolved health problem with an urgent medical need. MPM is histologically classified as (i) epithelial (50-70\% of cases), (ii) mesenchymal or sarcomatous ( $7-20 \%$ of cases), and (iii) mixed or biphasic (20-35\% of cases), (Johansson et al., 1996). Currently, no actionable targets can be exploited to effectively treat MPM and conventional chemotherapy represents the only feasible ther- 
apeutic approach for advanced diseases. The use of pemetrexed (PEM) in combination with cisplatin (Vogelzang et al., 2003) has fostered a major advance in the treatment of MPM, even though the objective radiological response rate is only about 40\% (Lustgarten et al., 2013). Hence, the majority of patients who receive the drug are exposed to its toxic side effects (and considerable costs) without radiographic or clear clinical benefits. Given the lack of effective treatments for MPM: the prognosis is invariably poor, averaging around 1 year of survival from diagnosis (Carbone et al., 2012). Modern targeted therapies that have shown benefit in other human tumors - e.g. lung cancers - have so far failed in MPM. This has led to MPM being listed an "orphan disease" by the EU (Bononi et al., 2015).

Conventional treatments for BOS and MPM are poorly effective mainly due to their systemic administration combined with their nontargeted nature, resulting in unpredictable biodistribution, insufficient drug accumulation in the thorax, limited efficacy, and systemic toxicity. In these diseases beside the predictable impact on survival, the local approach is believed to reduce the toxicity related to systemic treatment and to allow an optimal intrathoracic biodistribution.

Gold nanoparticles (GNPs) are among the most intensely studied nanomaterials due to their unique size-dependent electronic and optical properties (Giljohann DA, 2010 and Lu Y, 2012) combined with a great potential in a broad range of biomedical applications (Sperling RA, 2008 and Ghosh P, 2008). Indeed, GNPs exhibit multiple different properties of the gold core at the nanoscale, which render them applicable in medical imaging and therapy as contrast agents, targeted diagnostic tool, radio/photo-termal therapeutics, and can be employed as drug/gene delivery vehicles. Hydrophobic GNPs are produced by chemical reduction of gold salt to colloidal gold in the presence of a capping ligand in non-polar solvents, thus obtaining highly stable NPs, usually ranging in size from 1 to $5 \mathrm{~nm}$. However, further surface functionalization is needed to assure high biocompatibility and low cytotoxicity, which is normally obtained by amphiphile coating with polyethylene glycol (PEG). This functionalization prevents nonspecific protein adsorption on NPs in vivo, undesired uptake by the reticulo-endothelial system and prolonged half-life (Chen YS, 2009 and Longmire M, 2008). In addition, when targeting to specific cell types is required, antibodies, peptides, aptamers and small molecules can be easily attached to their surface. 
In our approach we engineered GNPs, which can be loaded with specific immunosuppressive/anti-proliferative drug (everolimus for BOS and pemetrexed for MPM), specifically targeted to the cells responsible of the pathological process (fibroblastoid-like mesenchymal cells for BOS and malignant mesothelial cells for MPM), and suitable for local administration (inhalatory route for BOS and intrapleuric administration for MPM).

As for BOS, we isolated mesenchymal cells (MCs) responsible of the pathogenic processes involved in BOS from bronchoalveolar lavage (BAL) of lung recipients. MCs isolated were characterized and we identified a possible target surface marker, CD44, whose expression ranged between $84 \%$ and $99 \%$ of isolated cells, but was not expressed by epithelial lung cells.

Our group (Cova et al., 2015) also demonstrated in vitro that engineered GNPs decorated with an antibody anti-CD44 expressed on MCs surface (GNP-HC) and loaded with the immunosuppressive drug, everolimus (GNP-HCe) were able to specifically enter into the cells (Fig. 1A), inhibit proliferation and induce apoptosis. The effect was more relevant than that obtained by treatment with everolimus $(0.003 \mu \mathrm{g} / \mathrm{ml})$ alone in the same experimental conditions. In order to exclude a possible toxic action of GNPs on near-positioned epithelial cells, we proved that our engineered nanoparticles had no effect on 16HBE bronchoalveolar epithelial cell line (Cova et al., 2015).
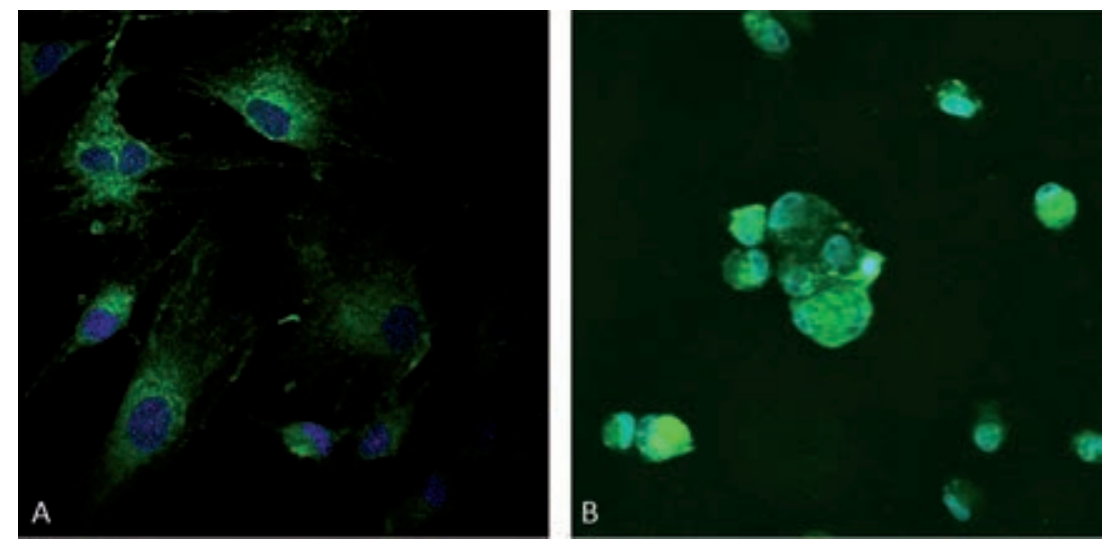

Fig. 1. Half-chain GNPs with everolimus internalization in MCs (A) and MPM

(B) cells. Images show that functionalized nanoparticles are able to enter the cells within $1 \mathrm{~h}$. 
Moreover, the long lasting action of drug-loaded nanoparticles was due to the slow release, up to 8 days, as proved by experiments performed into PBS buffer ( $\mathrm{pH} 7.4$ ) containing $2 \%$ bovine serum albumin. Since inflammatory response plays a pivotal role in BOS onset, we evaluated the in vitro effects of different GNPs on macrophages, neutrophils and lymphocytes. Macrophages vitality (by MTT test) was significantly inhibited $(\mathrm{p}<0.01)$ in presence of GNP-HCe starting from $24 \mathrm{~h}$ up to $72 \mathrm{~h}$. IL-8 production was not increased demonstrating no activation by GNP-HCe. Neutrophils did not show differences in apoptotic rate and elastase release. Lymphocyte proliferation was not changed while apoptosis was significantly increased $(\mathrm{p}<0.001)$ after $8 \mathrm{~h}$ and $24 \mathrm{~h}$ incubation. INF- $\gamma, \mathrm{IL}-17$ and IL-10 secretion was significantly $(\mathrm{p}<0.001)$ affected by GNP-HCe. Taken together these results state that GNP-HCe did not stimulate the inflammatory response thus preventing the exacerbation of the reactive milieu.

Localization and toxicity of GNP-HC and GNP-HCe in normal mice was proved by inhalation with a hand-made chamber. Mice were treated for $30 \mathrm{~min}$ a day for 5 days a week for 2 weeks with $50 \mu \mathrm{g} / \mathrm{ml}$ of Alexa 488 fluorescent marked GNP-HCe and GNP-HC. Control mice were treated with saline solution. Nanoparticle distribution was evaluated in lungs, kidney, spleen and liver by near-infrared (NIR) light imaging technology and showed that they were significantly distributed in lung tissue compared to control mice $(\mathrm{p}<0.001)$ and not in other organs. Analysis of BAL demonstrated that there wasn't a significant increase of IL-8 production by both GNP-HCe or GNP-HC, proving the absence of burst of inflammatory response. Subcellular distribution at pulmonary level assessed by electron microscopy showed that nanovecors localized in alveolar spaces, inside macrophages but not in pneumocytes (Fig. 2). Morphologic alterations induced by functionalized nanoparticles with/without drug were not recorded in all tested organs by histochemistry technique.

For MPM, preliminary data obtained on five primary MPM cell lines kindly supplied by Dr. Ymera Pignochino (IRCC Candiolo, Torino) and several bioptic MPM samples identified CD146, a cell adhesion molecule associated with advanced solid cancers as marker for GNPs targeting (expressed by $95-99 \%$ of MPM isolated cells). Engineered GNPs decorated with anti-CD146 and loaded with pemetrexed (GNP-HCPe) were tested in vitro on two MPM cell lines (MSTO-211H and H2452). Fluorescent GNP-HCPe uptake was evaluated by confocal microscopy showing that GNP-HCPe were able to 
enter into cells within $1 \mathrm{~h}$ and remained inside, proving the uptake specificity (Fig. 1B).

Biological effects have been evaluated by analyzing cell viability, after a single shot of $2 \mathrm{hr}$ incubation with GNP-HCPe or GNPs functionalized with CD146 Ab without PEM (GNP-HC) or PEM alone (100 nM), as previously described by us (Cova et al., 2015). GNP$\mathrm{HCPe}$ induced a significant decrease $(\mathrm{p}<0,001)$ of viability compared to untreated MSTO. A reduction of viability has been also observed in presence of GNP-HC suggesting a possible intriguing inhibitory action of CD146 Ab present on nanoparticle surface $(\mathrm{p}<0,001)$.

By this work, we proved for the first time that specifically engineered GNPs significantly inhibit proliferation and induce apoptosis of MCs, the main responsible of the fibroproliferative process underlying CLAD, the main cause of death after lung transplantation. We also demonstrated the absence of proinflammatory activity of these nanoparticles disclosing the possibility to administer functionalized drug-loaded GNPs by aerosolization without raising a further inflammatory response. In vivo experiments showed that functionalized nanoparticles administered by aerosolization were not taken by epithelial cells. Preliminary experiments on MPM cells also demonstrated the possibility to extend this new approach for the local treatment of other diseases. Indeed, this work opens new scenarios on the possibility to target a drug to specific cells involved in a pathological process avoiding systemic and side-effects on nearly positioned cells.
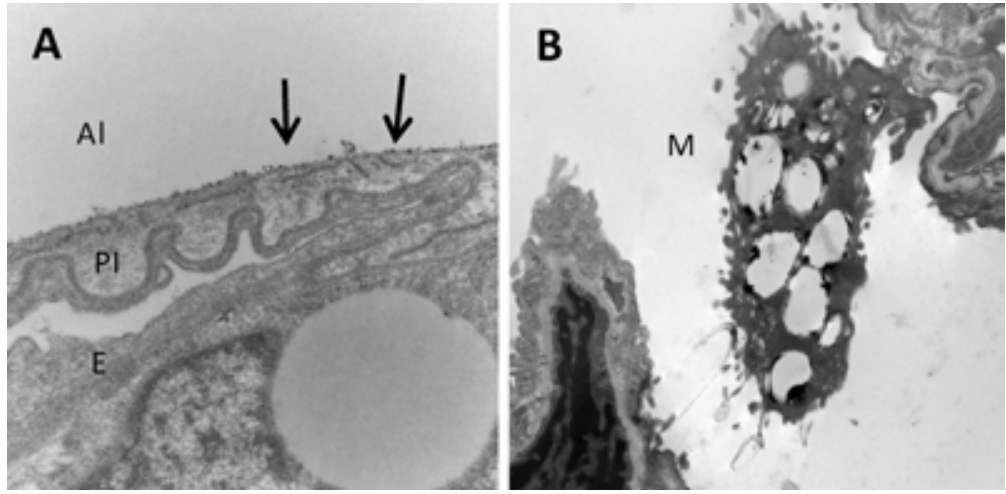

Fig. 2. Localization of GNP-HCe in mice lung. Inbaled nanoparticles are not inside pneumocytes $(A)$ and in bronchiolar epithelia but are uptaken by macrophages (B).

PI: type I pneumocyte, E: endothelium, Al: alveolus; M: alveolar macrophage. 


\section{REFERENCES}

Bononi A, Napolitano A, Pass HI, Yang H, Carbone M. Latest developments in our understanding of the pathogenesis of mesothelioma and the design of targeted therapies. Expert rev resp med. 2015;9(5):633-54.

Carbone M, Ly BH, Dodson RF, Pagano I, Morris PT, Dogan UA et al. Malignant mesothelioma: facts, myths, and bypotheses. Journal of Cellular Physiology. 2012;227(1):44-58.

Chen YS, Hung YC, Liau I, Huang GS. Assessment of the in vivo toxicity of gold nanoparticles. Nanoscale Res. Lett. 2009;4:858-864.

Cova E, Colombo M, Inghilleri S, Morosini M, Miserere S, Peñaranda-Avila J et al. Antibody-engineered nanoparticles selectively inbibit mesenchymal cells isolated from patients with chronic lung allograft dysfunction. Nanomedicine (Lond). 2015 Jan;10(1):9-23.

Ghosh P, Han G, De M, Kim CK, Rotello VM. Gold nanoparticles in delivery applications. Adv. Drug Delivery Rev. 2008;60:1307-1315.

Giljohann DA, Seferos DS, Daniel WL, Massich MD, Patel PC, Mirkin CA. Gold nanoparticles for biology and medicine. Angew. Chem. Int. Ed., 2010;49:32803294.

Johansson L, Lindén CJ. Aspects of bistopathologic subtype as a prognostic factor in 85 pleural mesotheliomas. Chest. 1996 Jan;109(1):109-14.

Longmire M, Choyke PL, Kobayashi H. Clearance properties of nano-sized particles and molecules as imaging agents: considerations and caveats. Nanomedicine, 2008;3:703-717.

Lu Y, Chen W. Sub-nanometre sized metal clusters: from synthetic challenges to the unique property discoveries. Chem. Soc. Rev., 2012;41:3594-3623.

Lustgarten DE, Deshpande C, Aggarwal C, Wang LC, Saloura V, Vachani A et al. Thymidylate synthase and folyl-polyglutamate synthase are not clinically useful markers of response to pemetrexed in patients with malignant pleural mesothelioma. J Thorac Oncol. 2013 Apr;8(4):469-77.

Robinson BM. Malignant pleural mesothelioma: an epidemiological perspective. Annals of cardiothoracic surgery. 2012;1(4):491-6.

Sperling RA, Rivera Gil P, Zhang F, Zanella M, Parak WJ. Biological applications of gold nanoparticles. Chem. Soc. Rev. 2008;37:1896-1908.

Todd JL, Palmer SM. Bronchiolitis obliterans syndrome: the final frontier for lung transplantation. Ches, 2011;140:502-508.

Vogelzang NJ, Rusthoven JJ, Symanowski J, Denham C, Kaukel E, Ruffie P et al. Phase III study of pemetrexed in combination with cisplatin versus cisplatin alone in patients with malignant pleural mesothelioma. J Clin Oncol. 2003 Jul 15;21 (14):2636-44.

Woodrow JP, Shlobin OA, Barnett SD, Burton N, Nathan SD. Comparison of bronchiolitis obliterans syndrome to other forms of chronic lung allograft dysfunction after lung transplantation. J Heart Lung Transplant. 2010;29(10):1159-64. 